Motrivivência v. 29, n. 50, p. 77-89, maio/2017

\title{
O QUE TANTO INTERESSA NO FUTEBOL E NO FUTSAL? Uma análise dos trabalhos de conclusão de curso em Educação Física
}

\author{
Talita Ferreira' \\ Evando Corlos Moreira
}

\section{RESUMO}

O objetivo deste trabalho, de caráter histórico-documental, é identificar e mapear os Trabalhos de Conclusão de Curso da Faculdade de Educação Física da Universidade Federal de Mato Grosso, entre os anos 2000 e 2010, que abordam as temáticas "futebol e futsal" em seus diferentes aspectos. Mais especificamente procurou-se identificar quais os anos de ocorrência e investigar as linhas de pesquisa temática da Educação Física as quais pertenciam os trabalhos, bem como as justificativas para tais escolhas. Percebeu-se que as temáticas tratadas nos estudos são diversificadas, mas não se privilegiam os estudos socioantropológicos, fazendo com que as pesquisas sobre futebol e futsal se distanciem do principal objeto da História: o homem.

Palavras-chave: Futebol; Futsal; Trabalho de Conclusão de Curso; Educação Física

1 Mestra em Educação Física. Professora do Curso de Educação Física do Centro Universitário de Várzea Grande (UNIVAG). Várzea Grande/ Mato Grosso, Brasil. E-mail: tali-gabi@hotmail.com

2 Doutor em Educação Física. Professor da Universidade Federal de Mato Grosso (UFMT). Cuiabá/Mato Grosso/ Brasil. E-mail: ecmmoreira@uol.com.br 


\section{INTRODUÇÃO}

"O que tanto interessa no futebol?" (WISNIK, 2008, p. 57). A questão inicial suscitada pelo professor de literatura da Universidade de São Paulo (USP), José Miguel Wisnik, que além de professor, também contribui com a esfera artística como compositor, músico e escritor, demonstra - sem dúvida - a amplitude temática e a pluralidade de sentidos que o futebol carrega em sua trajetória, estendida neste estudo ao futsal, por considerarmos seu significado e importância na cultura brasileira.

A partir da década de 1980, surgem os primeiros trabalhos acadêmicos sobre futebol com um olhar socioantropológico, isto é, o esporte passa a ser entendido como um fenômeno social próprio de determinadas culturas (SODRÉ, 1977; TUBINO, 2001; HELAL, 2011). Contudo, especificamente na área da Educação Física, o futebol e o futsal vêm sendo apresentado de diversas maneiras, entre elas - e principalmente -como prática de atividade física para promoção da saúde; parte da aprendizagem e refinamento motor; como ferramenta de socialização do indivíduo e, talvez, o mais vislumbrado pela sociedade de modo geral: a chance de ascender na vida por meio da profissionalização do esporte, focando a diretriz dadisciplina na promoção de atletas e/ou descoberta de novos talentos.

Considerando-se a efemeridade e transitoriedade do discurso futebolístico brasileiro, intenta-se por meio deste trabalho, de caráter histórico-documental,identificar e mapear os Trabalhos de Conclusão de Curso da Faculdade de Educação Física - FEF da Universidade Federal de Mato Grosso - UFMT, entre 2000 e 2010,cujas temáticas abordadas sejam o "futebole o futsal" em seus diferentes aspectos, para assim, ampliarmos as discussões na área sobre as múltiplas configurações desse esporte dentro da universidade o que, por sua vez, repercute na escola.

Em tempo, vale destacar que abordar o futebol e o futsal, implica reconhecer que o segundo, de acordo com Ré e Barbanti (2006), é uma das modalidades esportivas mais praticadas no Brasil, com apelo cultural tão forte quanto o futebol. Popularmente, é tido como uma reprodução do futebol em dimensões reduzidas, sendo que o futsal apresenta algumas particularidades nas regras e no menor tamanho e peso da bola, menor número de jogadores (cinco), número livre de substituições, cobrança de lateral com os pés, ausência do "impedimento", menor tamanho do gol, menor dimensão do espaço de jogo e piso rígido (RÉ, 2007).

\section{As monografias de graduação na Educação Física}

Não é de hoje que os cursos de graduação exigem a monografia como pré-requisito para a obtenção do título acadêmico. Entretanto, ainda que os alunos saibam desde o início que isso será exigido, a normalização e o aprofundamento da temática pesquisada, os deixam confusos e desorientados. Muitos ainda banalizam a elaboração da pesquisa, acreditando se tratar meramente de um procedimento burocrático (DEMO, 2009).

A característica básica da monografia é que seu conteúdo é o resultado de um processo de pesquisa. Espera-se que o aluno organize seu pensamento durante os anos 
de graduação, tornando evidente o processo de construção do conhecimento ao longo dos trabalhos acadêmicos e não apenas no produto final que é o trabalho pronto (SÁ; MAEDA; FARIA, 2009).

Nesse sentido, o aluno caminha na direção de sua autonomia de aprendizagem, tendo um professor que aja como orientador, lendo seus escritos e sugerindo modificações- se necessário- para que o aluno avance em sua pesquisa. E, nesse momento de busca por autonomia por parte do acadêmico, o professor deveatuar como mediador entre o conhecimento e seu orientando, viabilizando essa parceria pedagógica durante todo o processo de investigação.

Severino (2000, p. 18) define esse processo como:

[...] um instrumental extremamente útil e seguro para a gestação de uma postura amadurecida frente aos problemas científicos, políticos e filosóficos que nossa educação universitária enfrenta. [...] São instrumentos operacionais, sejam eles técnicos ou lógicos, mediante os quais os estudantes podem conseguir maior aprofundamento na ciência, nas artes ou na filosofia, o que, afinal, é o objetivo intrínseco do ensino e da aprendizagem universitária.

O processo de elaboração de uma monografia traduz-se para o acadêmico como uma somatória de habilidades que se agrega ao seu repertório de saberes, proporcionando o aprofundamento do estudo sobre determinada temática de forma organizada e metódica. Ou seja, é a possibilidade que o aluno tem para aprender a organizar seu conhecimento, sistematizando, questionando e reconstruindo o saber, que por vezes the foi apresentado de forma fragmentada durante o curso. A partir disso, o sujeito iniciará sua experiência na área da pesquisa e da reflexão, pois "[...] a exploração do patrimônio cultural e da realidade contextualizada torna-se uma exigência imprescindível ao processo pedagógico do ensino superior" (SEVERINO, 2000, p. 105).

Apesar de não ser novidade a exigência das monografias de graduação para obtenção do título acadêmico em Educação Física, pode-se dizer, de acordo com Melo (2000) que, foi a partir da década de 1980 que as monografias passaram a ser pré-requisito para a conclusão dos cursos de Educação Física, a fim de que representassem um estímulo à produção científica da área.

Concomitantemente, a partir da mesma década, a literatura futebolística inicia o seu processo de visibilidade no âmbito acadêmico:

A literatura acadêmica sobre o futebol brasileiro começou a se constituir alguns anos após o livro Universo do Futebol: Esporte e SociedadeBrasileira, organizado por Roberto DaMatta e publicado em 1982. Até aquele momento, os estudos eram escassos e havia tendência a se utilizar perspectiva "apocalíptica", nos termos de Eco (1979), influenciada pelo marxismo, que considerava o futebol variante do ópio dos povos, poderosa força de alienação dos dominados(HELAL, 2011, p. 14).

Contudo, ainda que a partir dessa época os trabalhos sobre futebol comecem a surgir no espaço acadêmico, ele não se dá com ênfase no âmbito da Educação Física, mas 
sim, dentro da área da Teoria da Comunicação, como o texto analítico de Muniz Sodré, publicado originalmente em 1977, que dedica o último capítulo ao futebol. O capítulo se intitula "Futebol, Teatro ou Televisão?" e trata da participação do torcedor no espetáculo, afirmando que esse é parte necessária do show futebolístico:

[...] seria um grande erro supor que a complexidade do futebol brasileiro possa cingir-se à conceituação de um 'aparelho esportivo', algo capaz de reproduzir o tempo todo, de modo reflexivo, a ideologia ou o sistema de relações do poder dominante (SODRÉ, 1984, p. 152).

Especificamente, no caso do curso licenciatura em Educação Física da UFMT, foi a partir do ano de 1997, com a mudança da estrutura curricular, que as monografias se tornaram pré-requisitos para a conclusão do curso, tendo as primeiras produções sido encontradas a partir de 2000, ano em que as primeiras turmas se formaram com a nova estrutura curricular, adentrando o século XXI, após tantas experiências futebolísticas retratadas pelas mídias cada vez mais avançadas.

Demo (1999) afirma que o aluno só realizará um bom trabalho de monografia ou de qualquer outro tipo se tiver consciência da importância da "autoria", e essa autoria não se constrói apenas com aulas de metodologia científica, mas sim, por intermédio de incentivo direcionado e estímulo de seu orientador/professor, que deve despertar esse interesse no acadêmico, para que, ao final, esse estudo conclusivo que encerra sua graduação não seja apenas mera repetição de tantos outros trabalhos que em nada contribuem para a excelência em pesquisa da Faculdade.

Dessa forma surge a seguinte indagação: o que tanto interessa no futebol e no futsal a ponto de tornarem-se temas de investigação em Trabalhos de Conclusão de Curso em Educação Física? Quais justificativas para a escolha desta temática?

\section{PROCEDIMENTOS METODOLÓGICOS}

A pesquisa adotou a abordagem qualitativa e caracterizou-se como descritiva, tendo em vista que permite observar, registrar, analisar e correlacionar fatos ou fenômenos sem a intenção de manipulá-los, descobrindo assim, a frequência de suas relações e conexões com outros fenômenos, sua natureza e caracterização (OLIVEIRA, 1999). Assim, registraram-se em quadros as monografias de graduação que se identificaram com quaisquer dos diversos elementos contextualizados do futebol e do futsal.

O delineamento desta pesquisa, de caráter histórico-documental, baseia-se no fato de que os trabalhos de graduação, como "documentos" nunca antes analisados, postulam que, enquanto fonte histórica, a monografia "exprime o poder da sociedade do passado sobre a memória e o futuro" (LE GOFF, 1996, p. 10), e como produto de uma sociedade, elas não são, portanto, produções isentas, ingênuas; traduzem leituras e interpretações vivenciadas por um determinado grupo de pessoas em certo tempo e espaço. Desta 
forma, o universo de pesquisa foi composto por 382 trabalhos de conclusão de curso da FEF/ UFMT, elaborados entre os anos 2000 e 2010 que foram o suporte de veiculação das informações sobre o futebol e o futsal no período selecionado. Tais trabalhos estavam impressos e compunham parte do acervo constituinte do Centro de Memória da Educação Física e do Esporte de Mato Grosso (CEMEFE-MT).

Para aseleção da amostra do universo escolhido optou-se em considerar os trabalhos que abordavam tanto o futebol em sua temática quanto o futsal. Desta escolha resultou o seguinte quantitativo: 19 trabalhos cuja temática abordou o futsal e 10 trabalhos que contemplaram o futebol. Sabe-se que, apesar das diferenças entre as modalidades, nos diversos aspectos que envolvem a tática, técnica e capacidades físicas,específicos às modalidades, preferiu-se considerar aspectos gerais do jogo/esporte que se caracteriza pela necessidade de execução de ações motoras em um contexto (show/espetáculo) de elevada instabilidade e imprevisibilidade de ações técnicas bastante semelhantes: passes, dribles, chute, cabeceio, desarme e domínio/controle de bola com diferentes partes do corpo e o gol, todos esses elementos presentes tanto no futsal quanto no futebol.

Para a análise dos dados, adotou-se a leitura criteriosa não só dos títulos/temas, como também dos resumos das monografias, com suas respectivas justificativas e objetivos, para que se pudesse realizar uma análise interpretativa dos dados obtidos que, para Severino (2000), implica na interpretação das ideias apresentadas pela amostra a partir da posição pessoal do autor, além de extrapolar os sentidos expressos no texto por meio de outras leituras.

Dessa maneira, para que obtivéssemos os resultados a seguir, agrupamos e apresentamos as categorizações sobressalentes inseridas no contexto do futebol e do futsal dos trabalhos de graduação já conhecidas no espaço da Educação Física, circunscritas numa estrutura que Tani (2011, p. 122) delimita como subárea de pesquisa, baseada no que existe no cenário internacional de níveis microscópicos para macroscópicos de análise:

[...] a Bioquímica do Exercício, a Fisiologia do Exercício, a Biomecânica, o Controle Motor, a Cineantropometria, o Desenvolvimento Motor, a Aprendizagem Motora, a Psicologia do Esporte/Atividade Física, a Sociologia do Esporte/Educação Física, a Antropologia do Esporte/Educação Física, a História do Esporte/Educação Física e a Filosofia do Esporte/Educação Física. Por outro lado, nas subáreas de pesquisas mais aplicadas tem-se por exemplo, a Nutrição aplicada ao Esporte/Atividade Física, o Treinamento Esportivo, a Administração Esportiva, a Pedagogia do Esporte/ Educação Física, a Educação Física Adaptada, a Educação Física Escolar, a Educação Física Laboral, o Lazer e Recreação, o Jornalismo Esportivo, o "Marketing" Esportivo e o Direito Esportivo.

É observável, no quadro a seguir, que a estrutura, ainda hoje, no nosso país, rege a produção, sistematização e disseminação de conhecimentos científicos, tendo como base as subáreas elencadas anteriormente. Vale ressaltar que, para fins da categorização adotada, utilizamos "Elementos Históricos e Socioantropológicos" para os trabalhos que estavam relacionados à Antropologia, História e/ou Sociologia; para os trabalhos cuja 
leitura permitiu transitar entre as subáreas que envolviam a motricidade, preferimos utilizar as três categorias correspondentes: "Controle, Desenvolvimento e Aprendizado Motor".

\section{RESULTADOS E DISCUSSÃO}

Quadro 1 - Monografias FEF/UFMT - ano 2000

\begin{tabular}{|l|l|}
\hline Título & Categoria \\
\hline $\begin{array}{l}\text { Futsal: esporte genuinamente brasileiro: } \\
\text { mudança de regras e suas implicações gerais }\end{array}$ & $\begin{array}{l}\text { Pedagogia do Esporte; } \\
\text { Elementos Históricos e Socioantropológicos }\end{array}$ \\
\hline
\end{tabular}

Fonte: Construção dos autores

Quadro 2 - Monografias FEF/UFMT - ano 2002

\begin{tabular}{|l|l|}
\hline Título & Categoria \\
\hline $\begin{array}{l}\text { O desenvolvimento da habilidade óculo-pedal na } \\
\text { iniciação do futebol }\end{array}$ & $\begin{array}{l}\text { Controle, Desenvolvimento } \\
\text { e Aprendizado Motor }\end{array}$ \\
\hline $\begin{array}{l}\text { Perfil antropométrico em crianças e adolescentes do } \\
\text { projeto bom de bola bom de escola: Mini-Estádio } \\
\text { Dom Aquino e Santa Isabel }\end{array}$ & Cineantropometria \\
\hline
\end{tabular}

Fonte: Construção dos autores

Quadro 3 - Monografias FEF/UFMT - ano 2003

\begin{tabular}{|l|l|}
\hline Título & Categoria \\
\hline O futsal e o treinamento desportivo & Treinamento Esportivo \\
\hline A importância da ludicidade na iniciação ao futsal & Pedagogia do Esporte/Recreação e Lazer \\
\hline $\begin{array}{l}\text { A recreação no futsal: e prevenção de doenças no } \\
\text { treinamento precoce }\end{array}$ & Recreação e Lazer/Treinamento Esportivo \\
\hline $\begin{array}{l}\text { Desenvolvimento e aperfeiçoamento das habilidades } \\
\text { motoras no futsal }\end{array}$ & $\begin{array}{l}\text { Controle, Desenvolvimento } \\
\text { e Aprendizado Motor }\end{array}$ \\
\hline
\end{tabular}

Fonte: Construção dos autores 
V. $29, n^{\circ} 50$, maio/2017

Quadro 4 - Monografias FEF/UFMT - ano 2004

\begin{tabular}{|l|l|}
\hline Título & Categoria \\
\hline $\begin{array}{l}\text { As valências físicas: velocidade de reação, } \\
\text { agilidade e força explosiva no treinamento } \\
\text { de goleiro da modalidade de futebol }\end{array}$ & $\begin{array}{l}\text { Controle, Desenvolvimento e } \\
\text { Aprendizado Motor /Treinamento } \\
\text { Esportivo }\end{array}$ \\
\hline $\begin{array}{l}\text { Efeitos na agilidade através do desenvolvimento } \\
\text { de seus fatores influenciadores num programa de } \\
\text { atividades com crianças na faixa etária de sete a } \\
\text { oito anos praticantes de futsal }\end{array}$ & $\begin{array}{l}\text { Controle, Desenvolvimento e } \\
\text { Aprendizado Motor }\end{array}$ \\
\hline $\begin{array}{l}\text { Os efeitos de um programa de alongamento } \\
\text { em estudantes do sexo feminino praticantes } \\
\text { de Futsal na faixa etária de } 14 \text { a } 17 \text { anos }\end{array}$ & $\begin{array}{l}\text { Controle, Desenvolvimento e } \\
\text { Aprendizado Motor }\end{array}$ \\
\hline Iniciação desportiva para crianças de 9 e 10 anos: futsal & Treinamento Esportivo \\
\hline $\begin{array}{l}\text { Futebol para iniciantes: uma proposição } \\
\text { a partir de atividades lúdicas }\end{array}$ & $\begin{array}{l}\text { Recreação e Lazer/ Treinamento } \\
\text { Esportivo }\end{array}$ \\
\hline
\end{tabular}

Fonte: Construção dos autores

Quadro 5 - Monografias FEF/UFMT - ano 2005

\begin{tabular}{|l|l|}
\hline Título & Categoria \\
\hline $\begin{array}{l}\text { A influência do futebol lazer em componentes de aptidão } \\
\text { física de bombeiros da área administrativa }\end{array}$ & $\begin{array}{l}\text { Recreação e Lazer/ Controle, } \\
\text { Desenvolvimento e } \\
\text { Aprendizado Motor }\end{array}$ \\
\hline $\begin{array}{l}\text { Treinamento fragmentado e globalizado, dentro dos } \\
\text { fundamentos técnicos passe, domínio, condução e } \\
\text { finalização - com garotos de } 14 \text { e } 15 \text { anos no futebol. }\end{array}$ & $\begin{array}{l}\text { Treinamento Esportivo/ Controle, } \\
\text { Desenvolvimento e } \\
\text { Aprendizado Motor }\end{array}$ \\
\hline $\begin{array}{l}\text { Ludicidade: o recurso utilizado como forma de motivação } \\
\text { para prática do futsal com alunos do ensino fundamental }\end{array}$ & $\begin{array}{l}\text { Recreação e Lazer e } \\
\text { Psicologia do Esporte }\end{array}$ \\
\hline $\begin{array}{l}\text { Programa de jogos e brincadeiras no desenvolvimento } \\
\text { motor para crianças de 09 a } 12 \text { anos em futsal }\end{array}$ & $\begin{array}{l}\text { Recreação e Lazer e Controle, } \\
\text { Desenvolvimento e } \\
\text { Aprendizado Motor }\end{array}$ \\
\hline $\begin{array}{l}\text { Testes realizados no } 3^{\circ} \text { grau da disciplina em Educação } \\
\text { Física I e Il dos acadêmicos matriculados em futsal }\end{array}$ & $\begin{array}{l}\text { Controle, Desenvolvimento e } \\
\text { Aprendizado Motor }\end{array}$ \\
\hline
\end{tabular}

Fonte: Construção dos autores

Quadro 6 - Monografias FEF/UFMT - ano 2006

\begin{tabular}{|l|l|}
\hline Título & Categoria \\
\hline $\begin{array}{l}\text { Treinamento para o chute de precisão } \\
\text { no futsal, categoria infantil }\end{array}$ & $\begin{array}{l}\text { Treinamento Esportivo/ Controle, } \\
\text { Desenvolvimento e } \\
\text { Aprendizado Motor }\end{array}$ \\
\hline
\end{tabular}

Fonte: Construção dos autores 
Quadro 7 - Monografias FEF/UFMT - ano 2007

\begin{tabular}{|l|l|}
\hline Título & Categoria \\
\hline $\begin{array}{l}\text { A influência de um programa de treinamento de futsal nos } \\
\text { níveis de agilidade em garotos de } 11 \text { e } 12 \text { anos de uma } \\
\text { iniciação esportiva }\end{array}$ & $\begin{array}{l}\text { Treinamento Esportivo/ } \\
\text { Controle, Desenvolvimento e } \\
\text { Aprendizado Motor }\end{array}$ \\
\hline $\begin{array}{l}\text { Prática do futsal nas escolas no desenvolvimento do } \\
\text { fundamento de chute ao gol com crianças de } 07 \text { a } 11 \text { anos }\end{array}$ & $\begin{array}{l}\text { Controle, Desenvolvimento e } \\
\text { Aprendizado Motor }\end{array}$ \\
\hline $\begin{array}{l}\text { Influência de prática desportiva futebol nos níveis de estresse de de } \\
\text { policiais militares }\end{array}$ & $\begin{array}{l}\text { Psicologia do Esporte/ } \\
\text { Atividade Física }\end{array}$ \\
\hline
\end{tabular}

Fonte: Construção dos autores

Quadro 8 - Monografias FEF/UFMT - ano 2008

\begin{tabular}{|l|l|}
\hline Título & Categoria \\
\hline $\begin{array}{l}\text { A Influência do treinamento de velocidade na } \\
\text { precisão no passe rasteiro do jogador de futsal } \\
\text { categoria mirim } 11 \text { a } 12 \text { anos }\end{array}$ & $\begin{array}{l}\text { Treinamento Esportivo/ Controle, } \\
\text { Desenvolvimento e Aprendizado Motor }\end{array}$ \\
\hline $\begin{array}{l}\text { Influência do treinamento aeróbio e anaeróbio na } \\
\text { composição corporal de jogadores de futebol com } \\
\text { idade } 16 \text { e } 17 \text { anos }\end{array}$ & $\begin{array}{l}\text { Treinamento Esportivo/Bioquímica/ } \\
\text { Fisiologia do Exercício/ } \\
\text { Cineantropometria }\end{array}$ \\
\hline $\begin{array}{l}\text { A influência de um programa de desenvolvimento do } \\
\text { fundamento passe com a parte interna do pé usando } \\
\text { a perna de menor habilidade motora em crianças na } \\
\text { faixa etária de } 10 \text { a } 12 \text { anos }\end{array}$ & $\begin{array}{l}\text { Controle, Desenvolvimento e } \\
\text { Aprendizado Motor }\end{array}$ \\
\hline $\begin{array}{l}\text { A influência da prática de futsal nos níveis de estresse } \\
\text { em adolescentes na faixa etária de } 11 \text { a } 13 \text { anos }\end{array}$ & $\begin{array}{l}\text { Psicologia do Esporte/Fisiologia do } \\
\text { Exercício }\end{array}$ \\
\hline $\begin{array}{l}\text { Os efeitos de um programa na execução de precisão } \\
\text { do fundamento passe na modalidade futsal em } \\
\text { meninos na faixa etária de } 13 \text { a } 15 \text { anos }\end{array}$ & $\begin{array}{l}\text { Treinamento Esportivo/ Controle, } \\
\text { Desenvolvimento e Aprendizado Motor }\end{array}$ \\
\hline $\begin{array}{l}\text { A influência de técnicas básicas de relaxamento } \\
\text { e alongamento nos níveis de estresse em atletas } \\
\text { praticantes de futebol da categoria sub-15 }\end{array}$ & $\begin{array}{l}\text { Treinamento Esportivo/Fisiologia do } \\
\text { Exercício }\end{array}$ \\
\hline $\begin{array}{l}\text { A influência da agilidade e velocidade na precisão do } \\
\text { chute com crianças de } 11 \text { a } 12 \text { anos na modalidade futsal }\end{array}$ & $\begin{array}{l}\text { Treinamento Esportivo e Controle, } \\
\text { Desenvolvimento e Aprendizado Motor }\end{array}$ \\
\hline
\end{tabular}

Fonte: Construção dos autores

Quadro 8 - Monografias FEF/UFMT - ano 2008

\begin{tabular}{|l|l|}
\hline Título & Categoria \\
\hline Fanatismo e futebol: características dos torcedores & $\begin{array}{l}\text { Elementos históricos e } \\
\text { socioantropológicos }\end{array}$ \\
\hline
\end{tabular}

Fonte: Construção dos autores 
Foi possível constatar que durante dez anos (2000 a 2010), dentre os trabalhos encontrados e analisados, apresentados pelos egressos do curso de Educação Física, apenas 29 (vinte e nove) abordaram a temática futebol e/ ou futsal, de um total de 382 monografias de conclusão de curso, o que nos leva a repensar essa questão arraigada de que o professor da escola, de modo geral, só trabalha o futebol/ futsal e, talvez, esse motivo venha do seu processo formativo. Aprende-se futebol, fala-se de futebol, assistimos ao futebol, ensinamos o futebol... mas será que realmente "estudamos" o futebol? Até que ponto vai o interesse acadêmico pelo futebol/ futsal? Questões que merecem outra análise, em outros trabalhos.

É importante destacar, infelizmente, que não se nota em nenhum dos trabalhos a preocupação em compreender como se processou o apego do mato-grossensepor esse esporte, ou ainda, como se deu historicamente a entrada desse tão disseminado esporte na região de Mato Grosso, tendo em vista ainda que são raras as discussões sobre as construções futebolísticas quanto à forma de vivenciar/ praticar, assistir ou apenas entender o futebol brasileiro desde a "pátria em chuteiras" de Nelson Rodriges (1912 - 1980), pelo menos numa perspectiva da micro-história.

Não identificamos trabalhos durante esse período que abordassem o esporte como valor social, símbolo nacional ou bem cultural, exceto por dois trabalhos apresentados que, por coincidência iniciaram e fecharam os quadros de resultados (2000 e 2010) que abordam as mudanças de regrase a relação da torcida com o esporte.

Os trabalhos que tiveram em sua abordagemreferências à Recreação e ao Lazer inseridos na Educação Física e associados ao futebol ou futsal ainda foram mais expressivos que os Elementos Históricos e Socioantropológicos, já que foram encontrados cinco trabalhos nessa categoria.

Nesse sentido, nos trabalhos que perpassaram a ludicidade, compreendeu-se, a partir de uma leitura mais minuciosa, que o futebole o futsalforam analisados como jogo e não como esporte. E, nessa perspectiva, sabe-se que Johan Huizingafoi e continua sendo um dos autores mais citados em trabalhos sobre jogos e brincadeiras nas áreas da Educação Física e afins.

Huizinga (2004) aborda e define o jogo em suas mais diversas expressões, oferecendo parâmetros para que o professor possa tratar cientificamente este importante aspecto da vida social moderna -mesmo que em grande parte de sua obra não haja uma referência explícita à modernidade:

[...] uma atividade livre, conscientemente tomada como, não séria e exterior à vida habitual, mas ao mesmo tempo capaz de absorver o jogador de maneira intensa e total. É uma atividade desligada de todo e qualquer interesse material, com o qual não se pode obter qualquer lucro, praticada dentro de limites espaciais e temporais próprios, segundo uma certa ordem e certas regras. (HUIZINGA, 2004, p. 16).

Entretanto, nos Trabalhos de Conclusão de Curso que abordaram o futebol e o futsal como jogo, as ideias, conceitos e métodos também deixaram a desejar no aspecto socioantropológico do estudo para reforçar uma abordagem de contexto esportivo, 
priorizando as características formais do jogo, apresentando um referencial teórico inconsistente. Essa afirmação pode ser justificada a partir da leitura completa que ocorreu de alguns trabalhos, tendo em vista que somente o resumo não foi suficiente para enquadrá-los em uma das categorias. Assim, evidenciou-se a inconsistência teórico/ referencial de alguns deles, valendo-nos da oportunidade de tecermos comentários.

Pôde-se notar que a maioria dos trabalhos enquadrou-se na categoria Treinamento Esportivo e Controle, Desenvolvimento e Aprendizado Motor (20 trabalhos de um total de 29, aparecendo juntos em alguns deles e em outras isoladamente ou com outras subáreas), ainda que também tematizassem outros aspectos como ludicidade e concepções pedagógicas, estas não se destacavam.

Entende-se que o esporte na Educação Física não é apenas uma área de ordem motora e fundamentos técnicos, mas por meio desta, é possível estudar seu enraizamento social e sua significação cultural na qual se insere e neste contexto a Educação Física escolar não pode ser baseada somente no aspecto motor do indivíduo, mas sim em sua totalidade, um ser que pensa, sente e que age. Para Gonçalves (1994, p.141):

O movimento humano é mais do que o resultado da atuação das forças fisiológicas ou biomecânicas, ou de um processo de aprendizagem motora, e sim é o homem como um todo que se movimenta. A Educação Física não deve priorizar apenas o aspecto físico. Neste sentido o profissional deve estar sempre voltado para o desenvolvimento global dos seus alunos, tornando-os seres conscientes e críticos, inseridos nesta sociedade tão abrangente da qual ele é parte integrante e resultante.

Assim, considera-se que as formas de abordar o futebol e futsal nos TCCs, considerouos mesmos a partir do contexto atual, organizado a partir do profissionalismo, excluindo assim, o caráter histórico e socioantropológico de espontaneidade do jogo. Dessacralizou-se o futebol e o futsal tanto na escola, como na sociedade de modo geral, e de acordo com Huizinga (2004, p. 220): "[...] esta ligação [do jogo] com o ritual foi completamente eliminada, o esporte se tornou profano, foi dessacralizado sob todos os aspectos e deixou de possuir qualquer ligação com a estrutura da sociedade".

Entretanto, deve-se questionar - ou ao menos refletir - sobre a atuação profissional docente no que se refere à orientação dos trabalhos à época. Ainda que, a partir dos anos 80 e 90 a Educação Física tenha iniciado uma crise existencial à procura de propósitos voltados à sociedade, apresentando outras possibilidades de manifestação do esporte, tais como a educação, a participação e aperformance (TUBINO, 2001), ainda assim, os resquícios do período esportivista parecem ter deixado seu legado para alguns professores.

Entendendo que a responsabilidade na escassez das discussões sociológicas do futebol e do futsal nos cursos de graduação em Educação Física da UFMT advêm, primeiramente, da "formação dos formadores", já que a necessidade de ampliar conhecimentos e saberes e adequá-los ao processo educativo contemporâneo remete-se à responsabilidade dos docentes que se encontram nas instituições de ensino superior, questiona-se: de que maneira as informações dispostas no espaço acadêmico sobre futebol e futsal dialogam com 
o capital cultural (saberes/conhecimentos) e habitus dos docentes que atuam nos cursos de graduação em Educação Física? Essa é uma das questões que se sugere para ampliar as discussões na área posteriormente.

Nesse contexto e conjecturando que o futebol e o futsal adquiriram nos últimos tempos dimensões culturais que necessitam ser analisadas sob diferentes perspectivas, visamos ampliar discussões futuras a uma proposta estética, já que o fenômeno futebolístico expressa mudanças nas formas de apreender a realidade e altera a compreensão do exercício do poder e controle social midiático, suscitando que pensemos urgentemente nas interfaces entre a tecnologia, comunicação, estilo de vida e as novas maneiras de conceber as práticas corporais na atualidade, bem como a forma de disseminar esse conhecimento.

Se os diferentes currículos são influenciados por concepções de aprendizagem, da cultura, da sociedade e dos conhecimentos que ensinam, diferenciando-se inclusive pela ênfase que dão a esses elementos (NEIRA, 2008), então, o autor sugere que a aula de futebol nos cursos de Educação Física só se transformará num espaço de co-construção de conhecimentos se o professor for capaz de mudar e aprender. E, para isso, é preciso investigar a concepção sócio-histórica do futebol e o futsal no currículo dos cursos de graduação em Educação Física e dos professores atuantes no Ensino Superior, para que se compreenda de que maneira estes apresentam aos acadêmicos as disposições, valores, regras e outras intenções construídas historicamente na trajetória do futebol e do futsal.

\section{CONSIDERAÇÕES FINAIS}

A partir da apresentação dos resultados, é notório o quão silenciado têm sido os debates em torno da apropriação do saber e produção dos sentidos sobre o futebol e o futsal por meio de currículos que privilegiam esta ou aquela cultura; correntes críticas e teorias pós-críticas que questionam o conhecimento e a ação transformadora; conceitos baseados nos Estudos Culturais que resultam num discurso multifacetado que compreende a Educação Física como um componente engajado nesse contexto (NEIRA; NUNES, 2008). Não obstante, Neira (2008) contribui com a discussão inicial atribuindo alguns entraves sociológicos dos currículos dos cursos de Educação Física ao percurso curricular dos cursos de formação (inicial e contínua) de professores e demais egressos.

Muitas questões e análises relevantes à sociologia do esporte não puderam ser apontadas/realizadas no momento, mas, a partir do que foi apresentado, pode-se considerar que o futebol e o futsal, como conteúdos das aulas de Educação Física, devem estar inseridos em um contexto maior, abrangendo desde sua história, evolução, contextualização social, política e econômica, fundamentos, técnicas e regras, enfim, é necessário que se pesquise e busque as raízes da práxis, uma vez que, ainda que ele seja um único esporte, este está vinculado a uma concepção de mundo, de sociedade, de ser humano, de educação e de cultura.

Ainda que o futebol seja considerado o esporte coletivo mais popular do país e que tenha a capacidade de mobilizar um grande contingente humano em torno de uma 
causa comum, deve-se contextualizá-lo como conteúdo nas aulas de Educação Física, respeitando-se todas as suas especificidades e as de seus alunos/ praticantes/ jogadores/ torcedores/ expectadores/ brasileiros, a fim de que o reessignifiquemos dentro do ambiente sociocultural que o produz.

\section{REFERÊNCIAS}

DEMO, Pedro.Universidade e pesquisa: agonia de um antimodelo. Motrivivência, Florianópolis, ano 5, n. 5/6/7, dez., 1999.

. Saber pensar é questionar. Brasília: Liber Livro, 2009.

SÁ, Nívea Vasconcelos de Almeida; MAEDA, Ernesto Kenshi Carvalho; FARIA, Moacir Alves de. Diretrizes para elaboração de trabalhos acadêmicos. Disponível em: < http:// www.facsaoroque.br/novo/downloads/pdf/diretrizes_fac_050410.pdf >. Acesso em: 2 dez. 2013.

GONÇALVES, M. A. S. Sentir, pensar e agir: corporeidade e educação. Campinas, SP: Papirus, 1994.

HELAL, Ronaldo. Futebol e comunicação: a consolidação do campo acadêmico no Brasil. Comunicação, mídia e consumo. São Paulo, v. 8, n. 21, p. 11-37, 2011.

HUIZINGA, Johan. Homo ludens: o jogo como elemento da cultura. 5. ed. São Paulo: Perspectiva, 2004.

LE GOFF, Jacques. História e memória. Tradução Bernardo Leitão. 4. ed. Campinas, SP: UNICAMP, 1996.

MELO, Victor Andrade de. Monografias do bacharelado: resumos. Rio de Janeiro: UFRJ, 2000. NEIRA, Marcos Garcia. Formação para a docência: o lugar da educação física na educação básica. In: SCHNEIDER, Omar e colaborares. Educação física, esporte e sociedade: temas emergentes. São Cristóvão: Editora da UFS, 2008, vol. 2.

NEIRA, Marcos Garcia; NUNES, Mario Luiz Ferrari. Pedagogia da cultura corporal: crítica e alternativas. 2.ed. São Paulo, SP: Phorte, 2008.

OLIVEIRA, Silvio Luiz de. Metodologia da pesquisa. In: OLIVEIRA, Silvio Luiz de. Tratado de metodologia científica: projetos de pesquisa, tgi, tcc, monografias, dissertações e teses. 2. ed. São Paulo: Pioneira, 1999.

POLLAK, Michael. Memória, esquecimento e silêncio. Estudos Históricos. Rio de Janeiro, v. 2, n. 3, p. 3-15 1989.

RÉ, Alessandro Hervaldo Nicolai; BARBANTI, Valdir José. Uma visão macroscópica da influência das capacidades motoras no desempenho esportivo. In: SILVA, Luiz Roberto Rigolinda. Desempenho esportivo: treinamento com crianças e adolescentes. São Paulo: Phorte, 2006.

RÉ, Alessandro Hervaldo Nicolai. Desempenho de adolescentes no futsal: relações com medidas antropométricas, motoras e tempo de prática.125f. 2007. Tese (Doutorado em Educação Física). Escola de Educação Física e Esporte, Universidade de São Paulo, São Paulo, 2007. 
SEVERINO, Antonio Joaquim. Metodologia do trabalho científico. 21. ed. São Paulo: Cortez, 2000.

SODRÉ, Muniz. Futebol, teatro ou televisão. In: SODRÉ, Muniz. O monopólio da fala. Petrópolis: Vozes, 1984.

TANI, G. A Educação Física e o Esporte no contexto da universidade. Revista brasileira de educação física e esporte. São Paulo, v. 25, n. esp., p. 117-26, dez. 2011.

TUBINO, Manoel José Gomes. Dimensões sociais do esporte. 2. ed. São Paulo: Cortez, 2001. WISNIK, José Miguel. Veneno remédio: o futebol e o Brasil. São Paulo: Companhia das Letras, 2008.

WHAT DOES IT REALLY MATTER RELATED TO FOOTBALL AND FUTSAL? An analysis about final paper of Physical Education course

\section{ABSTRACT}

This study - considered historical and documentary - aimed to identify and map the final paper in the Physical Education course of the Federal University of Mato Grosso, between 2000 and 2010, that discussed the theme "football and futsal" in its different aspects. Specifically attempted to identify the year of occurrence and investigate the thematic lines of research of the Physical Education which were related to the final paper and analyze the reasons for such choices. The themes addressed in the studies were presented of diversified way but not favoring the socioanthropological studies, distancing the researches on football and futsal of the main object of history: the man.

Keywords: Football; Futsal; Final Paper; Physical Education

\section{¿LO QUE ENCANTA TANTO EN EL FÚTBOL Y FÚTBOL SALA? Análisis en los trabajos finales de la Educación Física}

\section{RESUMEN}

Este estudio - considerado histórico y documental - buscó identificar y mapear los trabajos finales en el curso de Educación Física de la Universidad Federal de Mato Grosso, entre 2000 y 2010, que discutió el tema "fútbol y fútbol sala" en sus diferentes aspectos. En particular intentado identificar el año de incidencia e investigar las líneas temáticas de investigación de la Educación Física que se relaciona con el trabajo final y analizar los motivos de esos decisiones. Los temas abordados em los estudios se presentaron de manera diversificada, pero no favoreciendo a los estúdios socioantropológicos, distanciándo del objeto principal de la Historia de lãs investigaciones sobre el fútbol y fútbol sala: el hombre.

Palabras clave: Fútbol; Fútbol Sala; Trabajos Finales; Educación Física 